\title{
Molecular Study of Acinetobacter baumannii Isolates for Metallo- $\beta$-Lactamases and Extended-Spectrum- $\beta$-Lactamases Genes in Intensive Care Unit, Mansoura University Hospital, Egypt
}

\author{
Nashwa M. Alkasaby ${ }^{1}$ and Maysaa El Sayed Zaki² \\ ${ }^{1}$ Medical Microbiology and Immunology Department, Faculty of Medicine, Mansoura University, Mansoura, Egypt \\ ${ }^{2}$ Clinical Pathology Department, Faculty of Medicine, Mansoura University, Mansoura, Egypt
}

Correspondence should be addressed to Nashwa M. Alkasaby; nashwakasby2003@yahoo.com

Received 25 December 2016; Revised 28 March 2017; Accepted 10 April 2017; Published 8 May 2017

Academic Editor: Todd R. Callaway

Copyright (C) 2017 Nashwa M. Alkasaby and Maysaa El Sayed Zaki. This is an open access article distributed under the Creative Commons Attribution License, which permits unrestricted use, distribution, and reproduction in any medium, provided the original work is properly cited.

\begin{abstract}
Acinetobacter baumannii (A. baumannii) has been known as a causative pathogen of hospital acquired infections. The aim of this study is to examine the presence of A. baumannii among clinical isolates from intensive care unit (ICU) in Mansoura University Hospital (MUH), its antibiotic resistance pattern, and prevalence of antibiotic resistance genes metallo- $\beta$-lactamases (MBLs) and extended-spectrum- $\beta$-lactamases (ESBLs) among A. baumannii isolates. A. baumannii was identified by colony morphology, API $20 \mathrm{E}$, and confirmed by detecting the bla OXA-51-like carbapenemase gene by PCR. Phenotypic expression of MBLs resistance was demonstrated by Combined Disk Test (CDT) in 273 isolates (97.5\%) and of ESBLs was demonstrated by double disc synergy method (DDST) in 6 isolates (2.1\%). MBLs genes were positive in 266 isolates (95\%) and ESBLs genes were positive in 8 isolates (2.9\%). The most frequent genes of MBLs studied genes were IMP (95.7\%) followed by SIM and GIM (47.1\% and 42.9\%; resp.). For ESBL genes, the most frequent gene was TEM (2.9\%). From this study, we conclude that multidrug resistant (MDR) A. baumannii with MBLs activity was the most common isolate. Careful monitoring for the presence of MDR A. baumannii among hospitalized patients is recommended to avoid wide dissemination of antibiotic resistance.
\end{abstract}

\section{Introduction}

Acinetobacter baumannii (A. baumannii) is a Gram-negative coccobacilli nonglucose fermentative opportunistic pathogen [1]. A. baumannii is one of the most important nosocomial pathogens because of its longevity in the hospital environment and ability to resist various antimicrobial agents and to colonize susceptible patients treated with broad-spectrum antibiotic [2]. It has been related to various sites of infections like urinary tract, skin and soft tissue infections, pneumonia, and bacteremia especially in immunosuppressed patients [35].

Multidrug resistant A. baumannii (MDR A. baumannii), defined as an $A$. baumannii strain resistant to at least three different groups, penicillins and cephalosporins (including inhibitor combinations), fluoroquinolones, and aminoglycosides, has emerged and has been reported worldwide to significantly increase the morbidity, mortality, and cost of treatment [6]. The incidence of MDR A. baumannii is increasing worldwide, including Europe, North America, Latin America, and Asia [7].

Acinetobacter spp. exhibit multidrug resistance through production of $\beta$-lactamases, alterations in outer membrane proteins (OMPs) and penicillin-binding proteins (PBPs), and increased activity of efflux pumps [8]. Resistance to $\beta$ lactams appears to be primarily caused by production of $\beta$ lactamases which include extended-spectrum- $\beta$-lactamases (ESBLs), metallo- $\beta$-lactamases (MBLs), and oxacillinases [3].

MBLs are classes of powerful enzymes called carbapenemases responsible for antibiotic resistance. Four groups of 
these enzymes have been described in A. baumannii, including IMP-like, SIM-1, NDM-type, and VIM-like carbapenemases. MBLs-encoding genes are located on integrons that can be transmitted from one bacterial species to another [ 9 , 10]. Extended-spectrum- $\beta$-lactamases (ESBLs) are encoded by TEM-type, SHV-type, and CTX-M-type genes; they are resistance to penicillins and third-generation cephalosporins [11].

The drug of choice to treat nosocomial infection caused by MDR A. baumannii is the carbapenems. However, there is an increasing rate of carbapenem-resistant $A$. baumannii around the world [12].

There are limited data about the prevalence of $A$. baumannii among clinical isolates from Egypt and its pattern of antibiotics resistance. Therefore, we have performed this study to examine the presence of $A$. baumannii among clinical isolate in intensive care units (ICU) from one Egyptian tertiary care hospital, its antibiotic resistance pattern, and the prevalence of antibiotic resistance genes MBLs and ESBLs.

\section{Material and Method}

This cross-sectional study was carried out in the main microbiology laboratory at Mansoura University Hospital, Egypt, between January 2014 and January 2016. The study was approved by Mansoura Faculty of Medicine ethical committee. Clinical samples were obtained from patients admitted to ICU including blood, urine, sputum endotracheal secretion, wound swabs, pus, and CSF.

2.1. Culture and Identification. The specimens were inoculated on blood agar, chocolate agar, and MacConkey agar medium and incubated for $24 \mathrm{~h}$ at $37 \mathrm{C}$. Culture growth was identified to be A. baumannii growth by colony morphology and API 20 E confirmed by detecting bla OXA-51 carbapenemase gene using PCR [13]. Antibiotics susceptibility tests were done followed by multiplex PCR for detection of MBLs genes and ESBLs genes.

\subsection{Antimicrobial Susceptibility}

2.2.1. Standard Disc Diffusion Technique. A. baumannii isolates were tested for the susceptibility to ceftazidime $(30 \mu \mathrm{g})$, cefepime $(30 \mu \mathrm{g})$, imipenem $(10 \mu \mathrm{g})$, meropenem $(10 \mu \mathrm{g})$, gentamicin $(10 \mu \mathrm{g})$, amikacin $(30 \mu \mathrm{g})$, ciprofloxacin $(5 \mu \mathrm{g})$, levofloxacin $(5 \mu \mathrm{g})$, sulfamethoxazole/trimethoprim $(1.25 / 23.75 \mu \mathrm{g})$, and piperacillin/tazobactam $(100 \mu \mathrm{g} / 10 \mu \mathrm{g})$.

These analyses were performed by standard disc diffusion technique and interpreted according to the Clinical and Laboratory Standards Institute (CLSI) guidelines [16].

2.2.2. E-Test (MIC Determination). The E-test was used to determine antimicrobial susceptibility and the minimum inhibitory concentration (MIC) for tigecycline and colistin susceptibility according to the CLSI guidelines. Minimum inhibitory concentration (MIC) breakpoints for colistin were resistance, $\geq 4 \mathrm{mg} / \mathrm{L}$, and susceptibility, $\leq 2 \mathrm{mg} / \mathrm{L}$, and for tigecycline were resistance, $\geq 8 \mathrm{mg} / \mathrm{L}$, and susceptibility, $\leq 2 \mathrm{mg} / \mathrm{L}$. E. coli ATCC 35218 and Pseudomonas aeruginosa ATCC 27853 were used in all tests as control strain [16].

\subsection{Phenotypic Detection of MBLs Activity}

2.3.1. Imipenem-EDTA Combined Disc Test (CDT). Isolates resistant to imipenem were selected for detection of MBLs enzymes by imipenem-EDTA combined disk method. The test isolates (opacity adjusted to $0.5 \mathrm{McF}$ arland opacity standard) were cultured on Mueller-Hinton agar plate as recommended by CLSI. After drying, two $10 \mu \mathrm{g}$ imipenem discs were placed on the culture plate with $20 \mathrm{~mm}$ distance from center to center of the discs. $10 \mu \mathrm{l}$ of $0.5 \mathrm{M}$ EDTA was added to one of the imipenem discs and incubated overnight. Isolates showing $\geq 7 \mathrm{~mm}$ increase in the inhibition zone size of imipenem-EDTA disc compared to the imipenem disc alone were considered as MBLs producers [17].

\subsection{Phenotypic Identification of ESBL Producing Isolates}

2.4.1. Double Disc Synergy Test (DDST). Isolates resistant to third-generation cephalosporins were tested for ESBLs production by CLSI double disc synergy method (DDST). Antibiotic disks containing ceftazidime $(30 \mu \mathrm{g})$, cefotaxime $(30 \mu \mathrm{g})$, ceftazidime $(30 \mu \mathrm{g})+$ clavulanic acid $(10 \mu \mathrm{g})$, and cefotaxime $(30 \mu \mathrm{g})+$ clavulanic $(10 \mu \mathrm{g})$ were used.

Pairs of disks (ceftazidime with ceftazidime/clavulanic acid and cefotaxime with cefotaxime/clavulanic) were placed on Muller-Hinton agar medium with $20 \mathrm{~mm}$ space between them.

According to the CLSI criteria and manufacturer instruction, the $\geq 5 \mathrm{~mm}$ inhibition zone of growth in ceftazidime/clavulanic acid and cefotaxime/clavulanic compared to ceftazidime and cefotaxime was regarded as an ESBLs producing isolate [18].

\subsection{Multiplex PCR}

2.5.1. DNA Extraction. Pure colonies of A. baumannii were used for DNA extraction by Qiagen kit according to the manufacturer recommendations and kept at $-70^{\circ} \mathrm{C}$ till amplification reactions.

\subsubsection{Polymerase Chain Reaction (PCR)}

(a) PCR for the Detection of blaOXA-51-Like Gene. Polymerase chain reaction (PCR) assay was performed for the detection of blaOXA-51-like gene, a 353-base-pair (bp) amplicon, as an internal gene for molecular confirmation of $A$. baumannii isolates at the species level primer sequence: $\mathrm{F} / 5^{\prime}$-TAA TGC TTT GAT CGG CCT TG- $3^{\prime}$, R/5' -TGG ATT GCA CTT CAT CTT GG-3' [13].

(b) Multiplex PCR. Multiplex PCR was used to screen for the following resistance genes as previously described $[14,15]$.

Metallo- $\beta$-lactamases are blaIMP, blaVIM, blaGIM, bla SPM, and blaSIM-1 and class A beta-lactamases are blaTEM, blaSHV, and blaCTX-M. Primers used in this study are listed in Table 1. For the amplification procedures we used 3 microns of the extracted DNA applied over 25 microns of ready to use master mix with 0.2 microns of Taq polymerase $5 \mathrm{U} / \mu \mathrm{l}$ (Qiagen) with $1 \mu \mathrm{l}$ of each primer $(10 \mathrm{pmol} / \mathrm{ml})$ from each reverse and forward primer. 
TABLE 1: Primers used for PCR amplification of the studied genes.

\begin{tabular}{|c|c|c|c|}
\hline Gene & Sequence & $\mathrm{bp}$ & Reference \\
\hline CTX-M & $\begin{array}{l}\text { F: ATGTGCAGTACCAGTAAGCGTCATGGC } \\
\text { R: TGGGTAAAATATGTCACCAGAACCAG }\end{array}$ & 593 & {$[14]$} \\
\hline SHV & $\begin{array}{l}\text { F: ATGCGTTATATTCGCCTGT } \\
\text { R: TGCTTTGTTATTCGGGCCAA }\end{array}$ & 747 & [14] \\
\hline TEM & $\begin{array}{l}\text { F: CGC CGC ATA CAC TAT TCT CAG AAT GA } \\
\text { R: ACG CTC ACC GGC TCC AGA TTT AT }\end{array}$ & 445 & [14] \\
\hline VIM & $\begin{array}{l}\text { F: GATGGTGTTTGGTCGCATA } \\
\text { R: CGA ATGCGCAGCACCAG }\end{array}$ & 390 & [15] \\
\hline IMP & $\begin{array}{l}\text { F: GGAATAGAGTGGCTTAAYTCTC } \\
\text { R: CCA AACYACTASGTTATCT }\end{array}$ & 188 & [15] \\
\hline SPM-1 & $\begin{array}{l}\text { F: AAAATCTGGGTACGCAAACG } \\
\text { R: ACATTATCCGCTGGAACAGG }\end{array}$ & 271 & [15] \\
\hline SIM-1 & $\begin{array}{l}\text { F: TAC AAGGGATTCGGCATCG } \\
\text { R: TAATGGCCTGTTCCCATGTG }\end{array}$ & 570 & [15] \\
\hline GIM-1 & $\begin{array}{l}\text { F: TCG ACACACCTTGGTCTGAA } \\
\text { R: TCG ACACACCTTGGTCTGAA }\end{array}$ & 477 & [15] \\
\hline
\end{tabular}

TABLE 2: Acinetobacter baumannii distribution according to the site of infection.

\begin{tabular}{lcc}
\hline Sample & Number & $\%$ \\
\hline Endotracheal secretion & 110 & 39.3 \\
Sputum & 66 & 23.8 \\
Pus/wound swab & 40 & 14.3 \\
Blood & 33 & 11.8 \\
Urine & 30 & 10.7 \\
CSF & 1 & 0.4 \\
\hline
\end{tabular}

For PCR detection of amplified genes, agarose gel electrophoresis of the amplified DNA product with $100 \mathrm{bp}$ size marker was carried out in a $2 \%$ agarose gel for $2 \mathrm{~h}$ at $80 \mathrm{~V}$ and stained with ethidium bromide and visualized under UV transillumination [19].

\section{Results}

This study included 280 of $A$. baumannii isolated from different clinical samples from intensive care unit, Mansoura University Hospitals during 24 months. A. baumannii was confirmed by detecting bla OXA-51 gene in all isolates. $A$. baumannii isolates were most frequently recovered from endotracheal secretion (39.3\%) followed by sputum (23.8\%), pus/wound swab (14.3\%), blood (11.8\%), urine (10.7\%), and cerebrospinal fluid $(0.4 \%)$, Table 2 .

A. baumannii isolates were highly resistant to imipenem, meropenem, ceftazidime, and cefepime with resistance rate of $95.7 \%, 95.7 \%, 96.4 \%$, and $97.1 \%$, respectively, Table 3 . Also, the isolates showed high frequency of resistance to ciprofloxacin, gentamicin, sulfamethoxazole/trimethoprim, piperacillin/tazobactam, and amikacin (93\%, 85\%, 89\%, and 95\%, resp.).

Regarding colistin and tigecycline sensitivity, lower resistance was reported for these antibiotics (3\% and $1.5 \%$, resp.).
TABle 3: Antibiotics resistant patterns in Acinetobacter baumannii isolates.

\begin{tabular}{lcc}
\hline Antibiotics & Number & $\%$ \\
\hline Ceftazidime & 270 & 96.4 \\
Cefepime & 272 & 97.1 \\
Imipenem & 268 & 95.7 \\
Meropenem & 268 & 95.7 \\
Ciprofloxacin & 260 & 92.9 \\
Gentamicin & 260 & 92.9 \\
Sulfamethoxazole/trimethoprim & 218 & 77.9 \\
Piperacillin/tazobactam & 250 & 89.2 \\
Amikacin & 250 & 89.2 \\
Colistin & 9 & 3.2 \\
Tigecycline & 5 & 1.8 \\
\hline
\end{tabular}

TABLE 4: MBLs genes detected in Acinetobacter baumannii isolates.

\begin{tabular}{lcc}
\hline Genes & Number & $\%$ \\
\hline IMP & 268 & 95.7 \\
SIM & 132 & 47.1 \\
GIM & 120 & 42.9 \\
VIM & 0 & 0 \\
SPM & 0 & 0 \\
\hline
\end{tabular}

The phenotypic expression of MBLs resistance was demonstrated by CDT in 273 isolates (97.5\%) and of ESBLs was demonstrated in 6 isolates by DDST $(2.1 \%)$.

Genotypes detection for the studied genes for MBLs was positive in 266 isolates (95\%) and for ESBLs was positive in 8 isolates (2.9\%). Totally $280 \mathrm{~A}$. baumannii isolates have been examined for $5 \mathrm{MBL}$ and 3 ESBLs encoding genes. For MBLs genes, the most frequent genes were IMP (95.7\%), followed by SIM and GIM (47.1\% and $42.9 \%$, resp.), Table 4 . The most frequent genes from ESBL studied genes were TEM (2.9\%), 
TABLE 5: ESBLs genes detected in Acinetobacter baumannii isolates.

\begin{tabular}{lcc}
\hline Genes & Number & $\%$ \\
\hline TEM & 8 & 2.9 \\
SHV & 6 & 2.1 \\
CTX-M & 5 & 1.8 \\
\hline
\end{tabular}

SHF (2.1\%), and CTX-M in 1.8\%, Table 5. Some of the isolates had more than one gene.

\section{Discussion}

Multidrug resistant (MDR) A. baumannii that are present in the ICU and in the hospital environment represent therapeutic problem because of resistance to most antimicrobial agents [1].

In the present study, A. baumannii was isolated most commonly from the respiratory tract specimen followed by wounds and blood. This is consistent with data presented by other studies where the major source of $A$. baumannii isolates was respiratory specimens followed by wounds [20, 21].

Antibiotic resistance rate was high for most antibiotic except for colistin and tigecycline. The resistance of $A$. baumannii isolates to cephalosporins in the present study was in accordance with another study conducted by Safari et al., 2013 [5]. Ciprofloxacin resistance rate $(92.9 \%)$ was similar to studies conducted in Egypt and India which showed resistance rate of $85 \%$ and $99 \%$, respectively $[22,23]$.

Regarding aminoglycoside, resistant rate is $90 \%$; this is in accordance with other studies [24]. This finding is a warrant index to the possibility of coexistence of genes responsible for aminoglycoside and carbapenem resistance on the same genetic elements that may explain high resistance level to the tested aminoglycosides in the present study [7].

Carbapenems are generally the last resort in the treatment of life-threatening infections caused by MDR A. baumannii.

A. baumannii strains isolated in the present study had high frequency resistance to imipenem, meropenem. The presence of high resistance to carbapenem has been reported previously in Egypt $[22,25,26]$ and Turkey [20]. This finding can be explained by inadequate adherence to infection control guideline in addition to inappropriate use of carbapenem [26].

The preliminary resistance pattern of the isolated $A$. baumannii directs the attention to the presence of MBLs that was proven by phenotypic study by Combined Disk Test (CDT) for MBLs with a high frequency of MBLs gene (95\%). Previous reports stated that MBLs production among $A$. baumannii range from $49 \%$ up to $99 \%$ [27-29].

In the present study the presence of phenotypic ESBLs was detected in $2.1 \%$ of the isolates. On the contrary, higher results were reported in previous studies for ESBL producers bacteria with range from $20 \%$ up to $85 \%$ [29-31].

Treatment of patients infected with MBLs producers is challenging due to the currently limited options. Colistin and tigecycline are currently the only treatment choice for these MDR A. baumannii. Fortunately our finding in the present study showed that resistance rate to colistin and tigecycline is low (3\% and $1.5 \%)$ and was in accordance with other studies $[32,33]$.

In our study, all isolated A. baumannii strains carried bla OX-51 gene and were confirmed as A. baumannii. This gene is considered as a natural component of the species and may be associated with resistance to carbapenems [34].

Genotypes detection of the studied genes for MBLs was positive in 266 isolates (95\%) and for ESBLs was positive in 8 isolates $(2.9 \%)$. Among MBLs, IMP gene was the most detected gene as reported previously in other studies $[35,36]$. IPM and VIM genes have been reported from different countries with different prevalence rate [37-39].

On the contrary, IPM and VIM genes were not detected in study conducted in Egypt by Fatouh and El-din 2014 [40]. SPM gene was not detected in the present study; this is in accordance with another study conducted in Iran by Moghadam et al. 2016 [41]. Among ESBLs, TEM gene was positive in $2.9 \%$ of $A$. baumannii isolates; higher result was reported (13.15\%) by Rezaee et al., 2013 [35].

\section{Conclusion}

MDR A. baumannii isolates with metallo- $\beta$-lactamases activities represent therapeutic problem in ICU.

The main gene encoding for these metallo- $\beta$-lactamases in our study was IMP. MDR A. baumannii showed high resistance rate to most of the available antimicrobial agents, except for tigecycline and colistin.

Careful monitoring for the presence of MDR A. baumannii among hospitalized patients is recommended to avoid wide dissemination of antibiotics resistance and to limit the indiscriminative use of cephalosporins and carbapenems in the hospital. Antibiotics Stewardship Program and infection control measures environment should be applied to minimize the emergence of multiple drug resistant bacteria.

Physician should treat infection and not colonization based on clinical signs and laboratory parameters indicating systemic inflammatory response/sepsis.

\section{Conflicts of Interest}

The authors declare that there are no conflicts of interest regarding the publication of this paper.

\section{References}

[1] F. Perez, A. M. Hujer, K. M. Hujer, B. K. Decker, P. N. Rather, and R. A. Bonomo, "Global challenge of multidrugresistant Acinetobacter baumanni," Antimicrobial Agents and Chemotherapy, vol. 51, no. 10, pp. 3471-3484, 2007.

[2] J. Yeom, J.-H. Shin, J.-Y. Yang, J. Kim, and G.-S. Hwang, "1H NMR-based metabolite profiling of planktonic and biofilm cells in acinetobacter baumannii 1656-2," PLoS ONE, vol. 8, no. 3, Article ID e57730, 2013.

[3] M. Noori, A. Karimi, F. Fallah et al., "High prevalence of metallo-beta-lactamase producing Acinetobacter baumannii isolated from two hospitals of Tehran, Iran," Archives of Pediatric Infectious Diseases, vol. 2, no. 3, Article ID e15439, 2014. 
[4] D. E. Karageorgopoulos, T. Kelesidis, I. Kelesidis, and M. E. Falagas, "Tigecycline for the treatment of multidrug-resistant (including carbapenem-resistant) Acinetobacter infections: a review of the scientific evidence," Journal of Antimicrobial Chemotherapy, vol. 62, no. 1, pp. 45-55, 2008.

[5] M. Safari, M. Saidijam, A. Bahador, R. Jafari, and M. Y. Alikhani, "High prevalence of multidrug resistance and metallo-betalactamase $(\mathrm{M} \beta \mathrm{L})$ producing Acinetobacter baumannii isolated from patients in ICU wards, Hamadan, Iran," Journal of Research in Health Sciences, vol. 13, no. 2, pp. 162-167, 2013.

[6] S.-C. Kuo, S.-C. Chang, H.-Y. Wang et al., "Emergence of extensively drug-resistant Acinetobacter baumannii complex over 10 years: Nationwide data from the Taiwan Surveillance of Antimicrobial Resistance (TSAR) program," BMC Infectious Diseases, vol. 12, article 200, 2012.

[7] C. Franklin, L. Liolios, and A. Y. Peleg, "Phenotypic detection of carbapenem-susceptible metallo- $\beta$-lactamase- producing gram-negative bacilli in the clinical laboratory," Journal of Clinical Microbiology, vol. 44, no. 9, pp. 3139-3144, 2006.

[8] G. M. Cerqueira and A. Y. Peleg, "Insights into Acinetobacter baumannii pathogenicity," IUBMB Life, vol. 63, no. 12, pp. 10551060, 2011.

[9] M. E. Falagas and D. E. Karageorgopoulos, "Pandrug resistance (PDR), extensive drug resistance (XDR), and multidrug resistance (MDR) among gram-negative bacilli: need for international harmonization in terminology," Clinical Infectious Diseases, vol. 46, no. 7, pp. 1121-1122, 2008.

[10] L. L. Maragakis and T. M. Perl, "Acinetobacter baumannii: epidemiology, antimicrobial resistance, and treatment options," Clinical Infectious Diseases, vol. 46, no. 8, pp. 1254-1263, 2008.

[11] F. Fallah, M. Noori, A. Hashemi et al., "Prevalence of $b l a_{\mathrm{NDM}}$, $b l a_{\mathrm{PER}}, b l a_{\mathrm{VEB}}, b l a_{\mathrm{IMP}}$, and $b l a_{\mathrm{VIM}}$ genes among Acinetobacter baumannii isolated from two hospitals of Tehran, Iran," Scientifica, vol. 2014, 2014.

[12] K. A. Sofy, A. E. Saafan, S. M. AbdelGhani, and M. A. Amin, "Phenotypic and genotypic characterization of different classes of $\beta$-lactamases amongst Acitobacter spp. Isolated from Egyptian hospitals., New Egyptian Journal of Microbiology, vol. 42, pp. 11-18, 2015.

[13] J. F. Turton, N. Woodford, J. Glover, S. Yarde, M. E. Kaufmann, and T. L. Pitt, "Identification of Acinetobacter baumannii by detection of the bla OXA-51-like carbapenemase gene intrinsic to this species," Journal of Clinical Microbiology, vol. 44, no. 8, pp. 2974-2976, 2006.

[14] H.-J. Monstein, Å. Östholm-Balkhed, M. V. Nilsson, M. Nilsson, K. Dornbusch, and L. E. Nilsson, "Multiplex PCR amplification assay for the detection of ${ }^{\text {bla }} \mathrm{SHV},{ }^{\text {bla }} \mathrm{TEM}$ and ${ }^{\text {bla }} \mathrm{CTX}-\mathrm{M}$ genes in Enterobacteriaceae," APMIS, vol. 115, no. 12, pp. 1400-1408, 2007.

[15] M. J. Ellington, J. Kistler, D. M. Livermore, and N. Woodford, "Multiplex PCR for rapid detection of genes encoding acquired metallo- $\beta$-lactamases," Journal of Antimicrobial Chemotherapy, vol. 59, no. 2, pp. 321-322, 2007.

[16] Clinical and Laboratory Standards Institute (CLSI), "Performance standards for antimicrobial susceptibility testing; twentythird informational supplement," Tech. Rep. M100-S23, CLSI, Wayne, Pa, USA, 2013.

[17] D. Yong, K. Lee, J. H. Yum, H. B. Shin, G. M. Rossolini, and Y. Chong, "Imipenem-EDTA disk method for differentiation of metallo- $\beta$-lactamase-producing clinical isolates of Pseudomonas spp. and Acinetobacter spp.", Journal of Clinical Microbiology, vol. 40, no. 10, pp. 3798-3801, 2002.
[18] K. S. Thomson, "Extended-spectrum- $\beta$-lactamase, AmpC, and carbapenemase issues," Journal of Clinical Microbiology, vol. 48, no. 4, pp. 1019-1025, 2010.

[19] N. Woodford, M. J. Ellington, J. M. Coelho et al., "Multiplex PCR for genes encoding prevalent OXA carbapenemases in Acinetobacter spp.", International Journal of Antimicrobial Agents, vol. 27, no. 4, pp. 351-353, 2006.

[20] C. Kulah, M. J. Mooij, F. Comert et al., "Characterisation of carbapenem-resistant Acinetobacter baumannii outbreak strains producing OXA-58 in Turkey," International Journal of Antimicrobial Agents, vol. 36, no. 2, pp. 114-118, 2010.

[21] B. Abdalhamid, H. Hassan, A. Itbaileh, and M. Shorman, "Characterization of carbapenem-resistant Acinetobacter baumannii clinical isolates in a tertiary care hospital in Saudi Arabia," The New Microbiologica, vol. 37, no. 1, pp. 65-73, 2014.

[22] M. H. Al-Agamy, N. G. Khalaf, M. M. Tawfick, A. M. Shibl, and A. E. Kholy, "Molecular characterization of carbapeneminsensitive Acinetobacter baumannii in Egypt," International Journal of Infectious Diseases, vol. 22, pp. 49-54, 2014.

[23] D. Rynga, M. Shariff, and M. Deb, "Phenotypic and molecular characterization of clinical isolates of Acinetobacter baumannii isolated from Delhi, India," Annals of Clinical Microbiology and Antimicrobials, vol. 14, no. 1, article no. 40, 2015.

[24] R. B. Patwardhan, P. K. Dhakephalkar, K. B. Niphadkar, and B. A. Chopade, "A study on nosocomial pathogens in ICU with special reference to mutiresistant Acinetobacter baumannii multiple plasmids," Indian Journal of Medical Research, vol. 128, pp. 178-187, 2008.

[25] S. H. Ahmed, S. F. Abdelwahab, A. M. Hasanen, and D. S. Mohammed, "Multidrug resistant Egyptian isolates of Acinetobacter baumannii," Journal of American Science, vol. 7, no. 1, pp. 1013-1019, 2011.

[26] M. Fouad, A. S. Attia, W. M. Tawakkol, and A. M. Hashem, "Emergence of carbapenem-resistant Acinetobacter baumannii harboring the OXA-23 carbapenemase in intensive care units of Egyptian hospitals," International Journal of Infectious Diseases, vol. 17, no. 12, pp. el252-e1254, 2013.

[27] F. Fallah, A. Taherpour, M. H. Vala, and A. Hashemi, "Global spread of New Delhi mettallo-beta-lactamase-1 (NDM-1)," Archives of Clinical Infectious Diseases, vol. 6, no. 4, pp. 171-177, 2012.

[28] M. Safari, A. S. Mozaffari Nejad, A. Bahador, R. Jafari, and M. Y. Alikhani, "Prevalence of ESBL and MBL encoding genes in Acinetobacter baumannii strains isolated from patients of intensive care units (ICU)," Saudi Journal of Biological Sciences, vol. 22, no. 4, pp. 424-429, 2015.

[29] A. Peymani, M. R. Nahaei, S. Farajnia et al., "High prevalence of metallo-b-lactamase-producing acinetobacter baumannii in a teaching hospital in Tabriz, Iran," Japanese Journal of Infectious Diseases, vol. 64, pp. 69-71, 2011.

[30] P. Owlia, L. Azimi, A. Gholami, B. Asghari, and A. R. Lari, "ESBL-and MBL-mediated resistance in Acinetobacter baumannii: a global threat to burn patients," Le Infezioni in Medicina, vol. 20, no. 3, pp. 182-187, 2012.

[31] P. Sacha, P. Wieczorek, D. Ojdana et al., "Susceptibility, phenotypes of resistance, and extended-spectrum beta-lactamases in Acinetobacter baumannii strains," Folia Histochemica et Cytobiologica, vol. 50, no. 1, pp. 46-51, 2012.

[32] SM. El-Ageery, MA. Abo-Shadi, AA. Alghaithy, MA. Ahmad, NH. Alsharif, and SA. Alharbi, "Epidemiological investigation of nosocomial infection with multidrug-resistant Acinetobacter 
baumannii," European Review for Medical and Pharmacological Sciences, vol. 16, pp. 1834-1839, 2012.

[33] N. Dai, Li. DZ, J. C. Chen et al., "Drug-resistant genes carried by Acinetobacter baumanii isolated from patients with lower respiratory tract infection," Chinese Medical Journal, vol. 123, no. 18, pp. 2571-2575, 2010.

[34] S. M. Amudhan, U. Sekar, K. Arunagiri, and B. Sekar, "OXA beta $\beta$-lactamase-mediated carbapenem resistance in Acinetobacter baumannii," Indian Journal of Medical Microbiology, vol. 29, no. 3, pp. 269-274, 2011.

[35] M. A. Rezaee, O. Pajand, M. R. Nahaei et al., "Prevalence of Ambler class A $\beta$-lactamases and ampC expression in cephalosporin-resistant isolates of Acinetobacter baumannii," Diagnostic Microbiology and Infectious Disease, vol. 76, no. 3, pp. 330-334, 2013.

[36] N. A. Al-Sweih, M. Al-Hubail, and V. O. Rotimi, "Three distinct clones of carbapenem-resistant Acinetobacter baumannii with high diversity of carbapenemases isolated from patients in two hospitals in Kuwait," Journal of Infection and Public Health, vol. 5, no. 1, pp. 102-108, 2012.

[37] Z. Chen, S. Qlu, Y. Wang et al., "Coexistence of blaNDM-1 with the prevalent blaOXA23 and blaIMP in pan-drug resistant acinetobacter baumannii isolates in China," Clinical Infectious Diseases, vol. 52, no. 5, pp. 692-693, 2011.

[38] K. Lee, W. G. Lee, Y. Uh, H. a. GY, J. Cho, and Y. Chong, "Korean Nationwide Surveillance of Antimicrobial Resistance Group. VIM-and IMP-type metallo-beta-lactamase-producing Pseudomonas spp. and Acinetobacter spp. Korean hospitals," Emerging Infectious Diseases, vol. 7, pp. 868-871, 2003.

[39] M. Shanthi Amudhan, U. Sekar, A. Kamalanathan, and S. Balaraman, "blaIMP and blaVIM mediated carbapenem resistance in pseudomonas and acinetobacter species in India," Journal of Infection in Developing Countries, vol. 6, no. 11, pp. 757-762, 2012.

[40] M. Fattouh and A. N. El-din, "Emergence of carbapenemresistant acinetobacter baumannii in the intensive care unit in Sohag University Hospital, Egypt," International Journal of Current Microbiology and Applied Sciences, vol. 3, no. 4, pp. 732744, 2014.

[41] M. N. Moghadam, M. Motamedifar, J. Sarvari, H. S. EbrahimSaraie, M. M. Same, and F. N. Moghadam, "Emergence of multidrug resistance and metallobetalactamase producing acinetobacter baumannii isolated from patients in Shiraz, Iran," Annals of Medical and Health Sciences Research, vol. 6, no. 3, pp. 162167, 2016. 

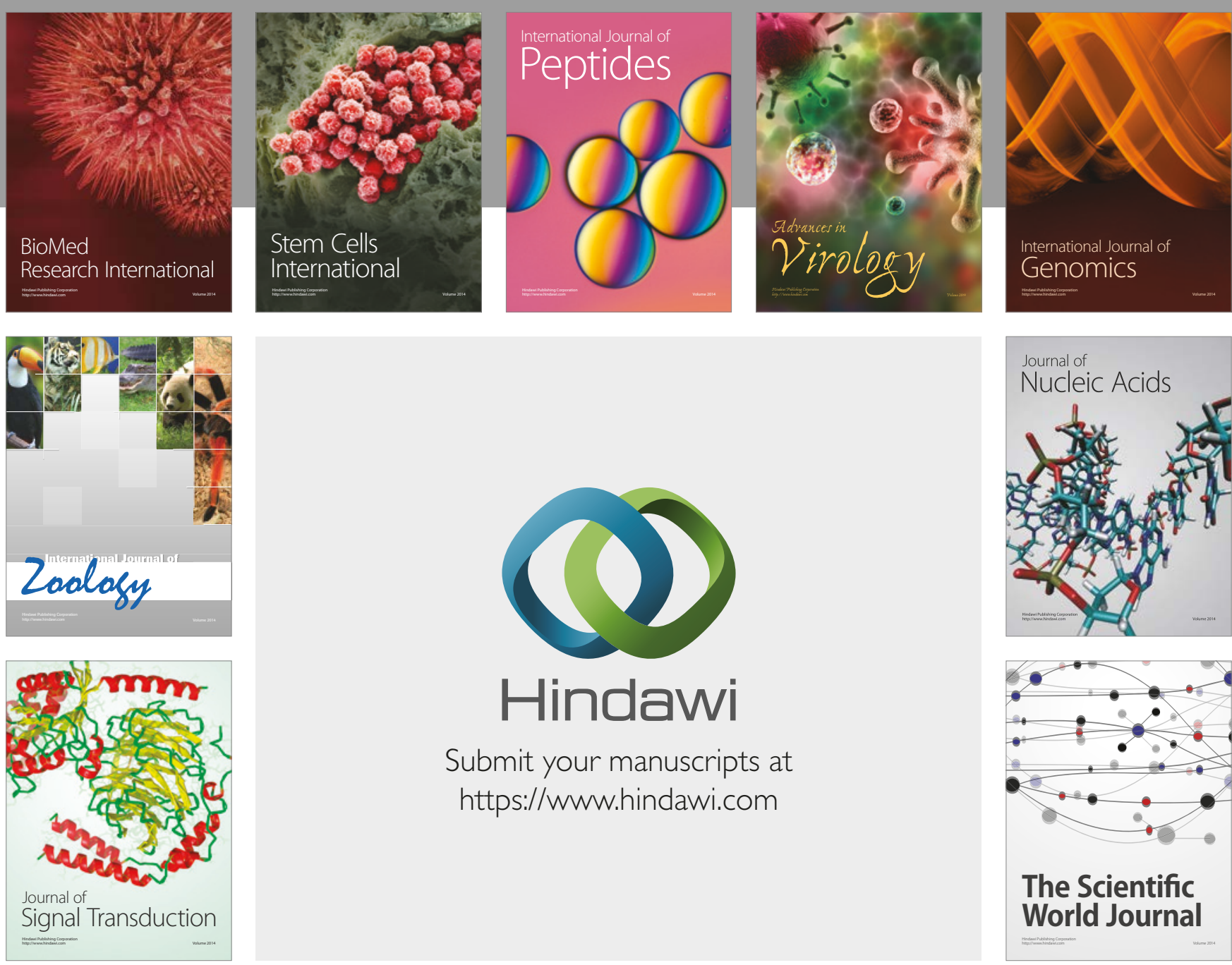

Submit your manuscripts at

https://www.hindawi.com
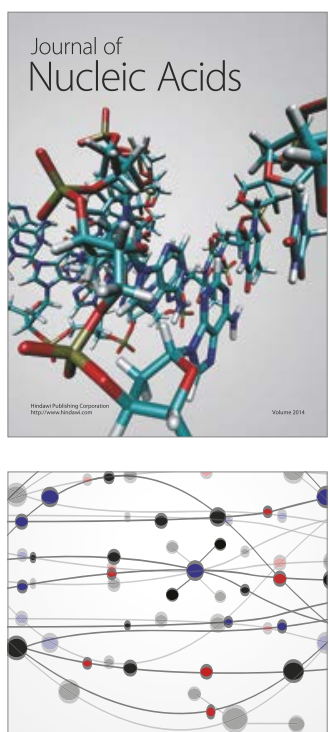

The Scientific World Journal

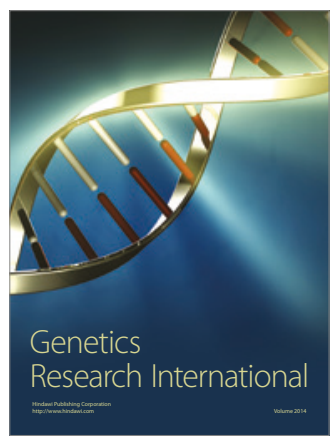

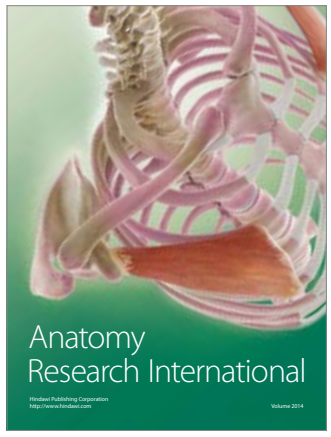

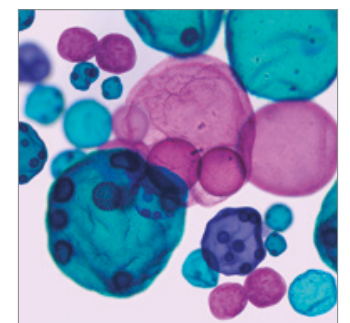

International Journal of Microbiology
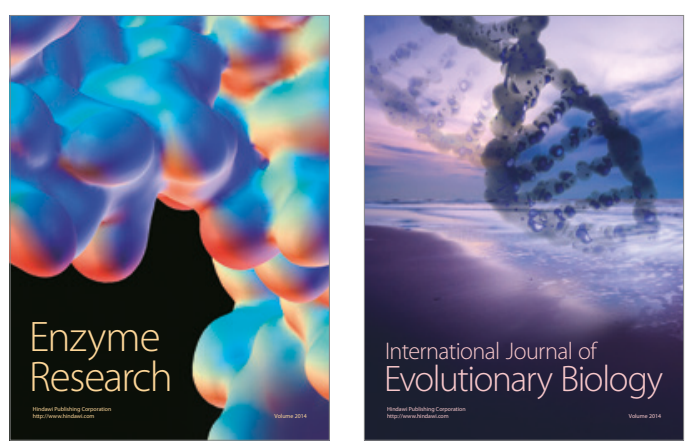
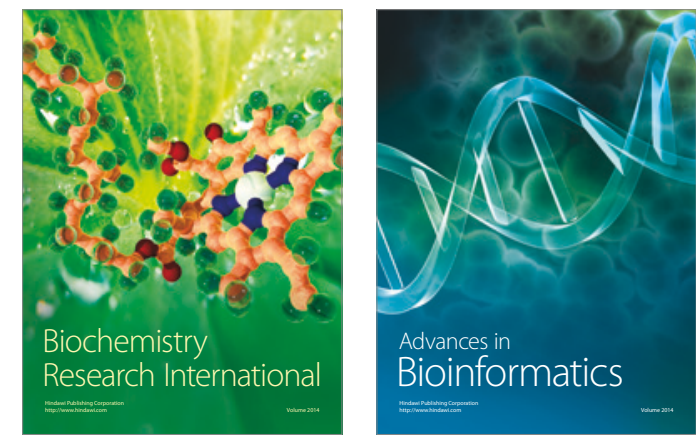

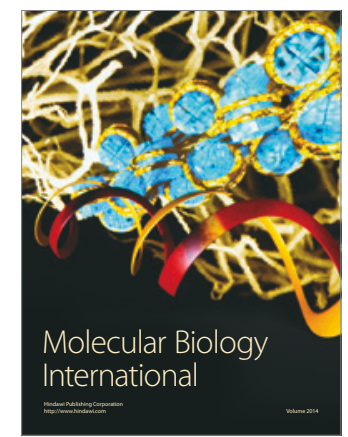

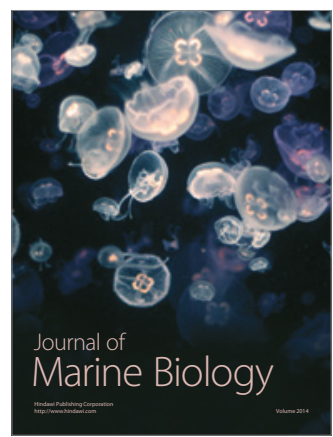

